\title{
Does Transformational Leadership matter during Organizational Change?
}

\author{
Paul Chou ${ }^{1}$
}

\begin{abstract}
Given that countless companies have failed to implement organizational change successfully, the success of organizational change is increasingly dependent upon employees' supportive attitudes and behaviors toward organizational change for a successfully planned change. Empirical research on the role and behaviors of leaders in a change context per se has been scarce. Hence, the aim of this study is to explore the mechanism through which transformational leadership influences employees' behavioral support for change. The results, obtained through analyzing data from 9 companies in Taiwan, revealed that transformational leadership not only affects directly employees' behavioral support for change, but also exerts its indirect effect on supportive behavior to change via self-efficacy. This study contributes to a better understanding of transformational leadership and self-efficacy within an organizational change context.
\end{abstract}

Key words: transformational leadership; self-efficacy; behavioral support for change.

\section{Introduction}

As modern organizations pursue changes to enhance their competitive positions and their survivability in competitive markets (Higgs \& Rowland, 2005), the successful implementation of organizational change has become an important management task. Nevertheless, countless companies have failed to implement organizational changes in recent decades (Higgs \& Rowland, 2005; Jaros, 2010; Judge, Thoresen, Pucik, \& Welbourne, 1999). These failures indicate that there is considerable room for researchers to provide insights into opportunities for improving the success of these changes (Parish, Cadwallader, \& Busch, 2007).

Given that individuals are the most important units in organizational change (Graetz \& Smith, 2010), the successful implementation of organizational change often requires employees' acceptance and support (Fedor, Caldwell, \& Herold, 2006; Miller, Johnson, \& Grau, 1994). In other words, employees' positive attitudes and supportive behavior are a necessary condition for successful planned change (Fedor et al., 2006; Meyer, Srinivas, Lai, \& Topolnytsky, 2007; Miller et al.,1994; Parish et al., 2007). However, there is limited understanding of the numerous factors associated with people's decision to support organizational change (Lamm \& Gordon, 2010).

Furthermore, literature on organizational change has been limited by the fact that past studies have tended to measure only the affective and attitudinal responses of employees to organizational change, rather than behavioral responses (Lamm \& Gordon, 2010). These facts point to the urgent need for researchers to investigate the impact of the 
affective and behavioral reactions of employees toward change (Parish, Cadwallader, \& Busch, 2007).

In essence, organizational change is stressful as it causes changes to, and demands readjustment of, average employees' normal routines. In this regard, leadership is seen as one of the most important variables affecting the attitudinal dimension of organizational life (Jaskyte, 2003). Moreover, leadership has been considered a critical element in organizational change (Yousef, 2000). With respect to the types of organizational leadership and their exchange relationship with followers, several reviews and metaanalyses have indicated that transformational leadership can result in individual, group, and unit performance beyond expectations (Sosik \& Godshalk, 2000).

Recently, there has been growing interest in understanding the influence of transformational leadership on followers. However, scholars have given little attention to the question of what characterizes transformational and what underlying mechanisms enable transformational leaders to affect followers and to arouse different types of motivation among their followers (Kirk, \& Dijk, 2007). Hence, this study aims to elucidate the underlying process through which transformational leadership exerts its influence on their followers' supportive behavior toward change in order to contribute to a better understanding of the inner workings of transformational leadership and organizational change.

In addition, past studies have tended to investigate the affective and attitudinal responses of employees to organizational change more than behavioral responses (Lamm \& Gordon, 2010). Accordingly, it is both important and beneficial to gain an understanding of the drivers of employees' supportive behavior for change (Fedor et al., 2006). In short, this study aims to answer calls for developing a greater understanding of the complexities of individuals' affective reactions under certain type of leadership during organizational change (Herold, Fedor, \& Caldwell, 2007) in the attempt to improve the success of organizational changes (Parish et al., 2007).

\section{Literature Review And Hypothesis Development \\ 2.1.1 Transformational leadership (TL)}

There is evidence that employees engage in an exchange relationship with both the organization as a whole and their immediate supervisor (Stinglhamber \& Vandenberghe, 2003). In many respects, the supervisor is the most immediate and salient person in the context of an individual's work, as employees tend to view actions by agents of the organization as actions of the organization itself (Livinson, 1965). Hence, the supervisor must have a direct influence on their subordinate's attitudes which, in turn, determine their behaviors through leading behaviors.

Burns (1978) and Bass (1985) distinguished transformational leaders from transactional leaders. Specifically, Bass and Avolio (1994) identified four behaviors associated with transformational leaders. They are (1) idealized influence, which can be defined as serving as a charismatic role model to followers; (2) inspirational motivation that involves articulation of a clear, appealing, and inspiring vision to followers; (3) intellectual stimulation of follower creativity by questioning assumptions and challenging the status quo; and (4) individual consideration, which involves attending to and supporting the individual needs of followers. In general, transformational leaders obtain support by inspiring their followers to identify with a vision that reaches beyond their 
own self-interest, whereas transactional leaders obtain cooperation by establishing economic exchanges with their followers (Judge \& Bono, 2000).

\subsubsection{Behavioral Support for Change (BSC)}

Behavioral support for change refers to behaviors that are consistent with the goals of change (Orth, 2002). According to Herscovitch and Meyer (2002), there are three kinds of behavior which are supportive to change: compliance, cooperation and championing. Compliance refers to employees' willingness to do what is required of them by the organization in implementing the change. Cooperation refers to employees' acceptance of the "spirit" of the change and willingness to do little extras to make it work. Finally, championing refers to employees' willingness to embrace the change and "sell" it to others.

In practice, the process of organizational change creates fear, uncertainty, and doubt (Jaskyte, 2003). Consequently, employees are skeptical about change and concerned about its outcomes during organizational change (Lau \& Woodman, 1995). This, in turn, results in a natural tendency for employees to resist, avoid, and devalue organizational change (Oreg, 2003). In this regard, employees' behavioral support for change is definitely a key to the successful implementation of organizational change (Fedor et al., 2006; Meyer, Srinivas, Lai, \& Topolnytsky, 2007; Miller, Johnson, \& Grau, 1994; Parish et al., 2007).

\subsubsection{Transformational Leadership and Behavioral Support for Change}

In the workplace, supervisors play an important role in structuring the work environment by providing information and feedback to employees (Griffin, Patterson, \& West, 2001) and by controlling the powerful rewards that acknowledge the employee's personal worth (Doby \& Caplan, 1995). As such, the social interaction between an employee and his/her immediate supervisor is the primary determinant of an employee's attitude and behavior in the workplace (Wayne, Shore, \& Liden, 1997). According to the concept of personifying the organization, the immediate supervisor's behaviors are likely to be perceived by employees as representative of organizational decisions (Griffin, Patterson, \& West, 2001). In this perspective, favorable or unfavorable treatment by the employees' immediate supervisors is interpreted as the organization's benevolent or malevolent orientation towards them (Loi, Ngo, \& Foley, 2006). Accordingly, the daily interaction between a leader and his/her subordinates may influence perceived organizational support as the employees' immediate supervisors are often seen as the source or distributor of discretionary rewards provided by an organization.

In theory, employees, once perceive organizational support via transformational leadeship, based on the norm of reciprocity, develop a generalized felt obligation to care about the organization's welfare and help the organization achieve its objectives (e.g., success of change) (Eisenberger et al., 2001). Put differently, employees who, because of trust in the organization (via transformational leadership), have positive perceptions of the outcomes of organizational change tend to motivate their behavioral support for organizational change. In short, transformational leadership is effective in enhancing subordinates' supportive behavior toward organizational change.

To summarize, it is reasonable to assume that an employee, who is under transformational leadership, tends to perceive the outcomes of organizational change 
positively which, in turn, will enhance supportive behavior to change. Thus, hypothesis 1 is stated as:

H1: There is a direct positive relationship between transformational and behavioral support for change.

\subsection{The mediating roles of Self-efficacy (SLF)}

According to Baron and Kenny (1986), the role of SLF as a mediator of the TLBSC relationship is supported, in part, by the links between: (1) TL and BSC, (2) TL and SLF, (3) SLF and BSC. Hence, the links mentioned above, except the link between TL and BSC which was discussed above, are discussed as follows.

\subsubsection{Transformational Leadership (TL) and Self-efficacy (SLF)}

For decades, self-efficacy has consistently been found to influence thought patterns, behaviors and emotional arousal (Armenakis, Harris, \& Mossholder, 1993). Self-efficacy is defined as an employee's belief in his/her capability to mobilize motivation, cognitive resources and the courses of action needed to exercise control over events in their lives (Wood \& Bandura, 1989). Based on this definition, self-efficacy defines the extent to which an individual believes him/herself to be capable of successfully performing a specific behavior or task (Bandura, 1986) and enables him/her to integrate cognitive, social, emotional and behavioral sub-skills, in order to accomplish a particular objective (Judge, Thoresen, Pucik, \& Welbourne, 1999). According to Bandura (1991), an individual's belief in their own efficacy influences the choices they make, their aspirations, the level of effort they will sustain on a given task and how positively or negatively they think when coping with change.

Bandura (1982) specified four sources of self-efficacy: Mastery experience, vicarious experience, verbal persuasion and emotional arousal. This study expects transformational leadership to have an effect on the four sources of efficacy judgments previously identified by Bandura (1986, 1997). For example, a transformational supervisor can provide opportunities for mastery/vicarious experiences to their subordinates, in addition to serving as a model of encouragement, through verbal persuasion (Schyns, 2004). Moreover, previous research supports the contention that transformational leaders can persuade employees that they are capable of producing expected outcomes (Tierney \& Farmer, 2002).In other words, a transformational leader in the workplace is perceived by recipients as a major organizational resource upon which they can rely when performing daily tasks. Specifically, during organizational change, the perceived availability of transformational leadership may enhance employees' confidence that the job will get done.

Moreover, individuals in organizations strive for self-esteem and a positive self-concept (Michel, Stemaier, \& Salvador, 2010). According to Michel et al. (2011), self-concept is derived from group membership and from the way in which the group to which one belongs is valued by others (i.e., supervisor, coworkers and the organization). Accordingly, it is reasonable to state that a transformational leader allows subordinates to feel confident in their ability to confront challenges and overcome problems successfully in the workplace, which in turn enhances their self-efficacy. Thus, this study assumes that there is a direct positive relationship between transformational leadership and selfefficacy. 


\subsubsection{Self-efficacy (SLF) and Behavioral Support for Change (BSC)}

Basically, organizational change is intended to alter key organizational variables that then affect the members of the organization and their work-related attitudes and behaviors (Jimmieson, Terry, \& Callan, 2004). Moreover, as noted above, the organizational change process creates fear, uncertainty and doubt (Graetz \& Smith, 2010; Jaskyte, 2003) which, in turn, results in a natural tendency for employees to resist, avoid, and devalue organizational change (Oreg, 2003). In this sense, the greater a person's selfefficacy, the more confident he or she is about being successful in a difficult task domain (organizational change in this case) (Prussia, Anderson, \& Manz, 1998). In other words, self-efficacy has a critical effect on an individual's perceived ability and willingness to exercise control in the workplace (Litt, 1988). Furthermore, employees with high selfefficacy are more prone to strive to complete a difficult task (e.g., organizational change) and less prone to give up when obstacles appear during organizational change (Schyns, 2004).

Theoretically, individuals with strong affective commitment to an organizational change initiative might show strong willingness to go above and beyond the call of duty to find ways to make the initiative work (Meyer \& Herscovitch, 2001). By the same token, those who confidence to exercise control during change and want to make efforts to ensure its success should be willing to do more than is required of them, even if it involves some personal sacrifice (Meyer \& Herscovitch, 2001; Meyer et al., 2007). Accordingly, it is reasonable to infer that employees with high self-efficacy are more prone to demonstrate behavioral support for change.

In summary, on the basis of all of the inferences previously discussed for the simple bivariate associations incorporated in the initial hypotheses, this study assumes that TL not only exerts effect on BSC directly, but also indirectly affects BSC via SLF . Therefore, hypothesis 2 is stated as:

H2: SLF mediates the relationship between transformational leadership and behavioral support for change.

\section{Methods}

\subsection{Participants}

Survey data for this study was collected from 9 companies locate at Hsinchu County, Taiwan. Procedure-wise, a total of 900 questionnaires with a cover letter explaining the purpose of the survey were sent to the HR head of 9 surveyed companies along with a return envelope to ensure that participants could send back their replies independent of their organizations. A total of 473 questionnaires were returned (53\% response rate), with 379 valid questionnaires after screening (42\%).

\subsection{Measures}

Unless otherwise stated, all responses were made on a 6-point scale ranging from (1) strongly disagree to (6) strongly agree.

\subsubsection{Transformational Leadership (TL)}

Transformational leadership was assessed through four dimensions, namely individual consideration, intellectual stimulation, inspirational motivation, and idealized influence, using Chou's (2013) 12 items which was adapted from Sosik and Godshalk's (2000) 15 items. The responses were measured along a 6-point Likert scale ranging from 
"strongly disagree" to "strongly agree" with respect to the respondent's certainty as to their immediate supervisor's leadership ability. The internal consistency of this 12-item scale was .97 in the current sample.

\subsubsection{Self-efficacy (SLF)}

Self-efficacy was measured using the ten items developed by Schwarzer, Bäßler, Kwiatek, Schröder \& Zhang (1997) (e.g., "I can always manage to solve difficult problems if I try hard enough"). The internal consistency of the ten-item scale was 0.94 for this sample.

\subsubsection{Behavioral Support for Change (BSC)}

Behavioral support for change was measured by three dimensions with the 17 items developed by Herscovitch and Meyer (2002) (e.g. "I adjust the way I do my job as required by this change" [compliance], "I work toward the change consistently" [cooperation], and "I encourage the participation of others in the change" [championing]). The internal consistency of this six-item scale was .96 in the current sample.

Overall, the strength of the internal consistency estimates of the variables in this study suggests homogeneity of the scale items.

\subsection{Analysis}

Before testing the study hypotheses, confirmatory factor analysis (CFA) was conducted with AMOS software (Arbuckle, 2003) to examine the convergent and discriminant validity of the study measures. Given the large number of items (39) relative to the sample size (379), the procedures recommended by Mathieu and Farr (1991) were followed by creating five composite indicators for SLF. For the indicators of TL and BSC, three sub-dimensions (i.e., idealized influence; inspirational motivation and individual consideration) and three sub-dimensions (i.e., compliance; championship and cooperation; intellectual stimulation), respectively, were used in order to maintain an adequate sample-size-to-parameter ratio (Landis, Beal, \& Tesluk, 2000).

Following the approach suggested by Andersen and Gerbing (1988), convergent validity is demonstrated when the path loading $(\lambda)$ from an item to its latent construct is significant and exceeds 0.50 . All path loading $(\lambda)$ in this study, as shown in Table 2, was above 0.50 (0.76-0.94). In addition, convergent validity is also adequate when the constructs have an average variance extracted (AVE) of at least 0.50 and composite reliability (CR) is greater than 0.6 (Hair, Anderson, Tatham, \& Black, 2006). As shown in Table 2, the square root of AVEs of all four constructs in this study exceeded 0.70 (0.890.94) and CRs of all four constructs exceeded 0.6 (0.89-.97). Thus, all constructs in our study demonstrate adequate convergent validity.

To assess discriminant validity, the procedures outlined by Fornell and Larcker (1981) were employed to examine whether the square root of AVE for the two constructs should exceed the correlation between the constructs. As shown in Table 2, the square root of AVE for the two constructs exceeded the correlation between the constructs. Thus, all tests of reliability and validity lead to the conclusion that the measures used in later statistical analyses fall within acceptable reliability and validity criteria.

In addition, given that the data were collected from a single source, the procedures of Harman's one-factor test recommended by Podsakoff, Mackenzie, Lee, and Podsakoff 
(2003) were conducted to test whether the hypothesized four-factor model was superior to the one-factor model in order to rule out the influence of common method bias. The result shows that the four-factor model $(\mathrm{GFI}=.96$; $\mathrm{CFI}=.99$; TLI $=.98$; RMSEA $=$ $.054)$ had a better fit than did the single-factor model (GFI= .51; CFI= .74; TLI = .68; RMSEA $=.237$ ). Thus, although this study acknowledges that common method variance may be present in the data, it does not appear that common method bias is a serious problem in this study.

\section{Results}

\subsection{Sample Characteristics}

Among the 9 companies, four are manufacturing companies and five are from service industry. As mentioned earlier, a total of 473 questionnaires were returned, with 379 valid questionnaires after screening (42\%). Descriptive statistics for the valid respondents are presented in Table 1.

Table 1. Descriptive profile of respondents

Gender

Job Rank

Age (years)

Seniority (years)

Education

Annual income (NT\$)
Male

$61 \%$

Female

$39 \%$

Managerial position

$19 \%$

Non-managerial position

$81 \%$

Under 30

$34 \%$

$31-40$

$47 \%$

41-50

$15 \%$

Over 50

$4 \%$

Over 15 years

$6 \%$

11-15 years

$14 \%$

5-10 years

$32 \%$

Under 5 years

$48 \%$

Masters

$15 \%$

University Degree

$49 \%$

Diploma

$24 \%$

High school

$12 \%$

Over $1.200,000$

$1 \%$

$800,001-1,200,000$

$2 \%$

$400,001-800,000$

$30 \%$

Less than 400,000
$67 \%$ 


\subsection{Hypothesis Testing}

Means, standard deviations, internal reliabilities, and intercorrelations among the variables are reported in Table 2. All measures show high internal reliabilities, with coefficient alphas ranging from .94 to .97 . The pattern of correlations is consistent with the hypothesized relationships. That is, TL has a statistically significant positive relationship with the potential mediator, $\operatorname{SLF}(0.63, \mathrm{p}<0.01)$, and with the outcome variables of BSC $(0.72, \mathrm{p}<0.01)$. Also, SLF has a statistically significant positive relationship with BSC $(0.79, \mathrm{p}<0.01)$.

Table 2. Descriptive Statistics and Correlations Among Study Variables

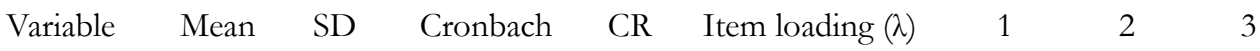

$$
\alpha \quad \text { (min.-Max.) }
$$

$\begin{array}{llllll}\text { 1. TL } & 4.31 & 1.03 & .97 & .97 & (.93-.94)\end{array}$

$\begin{array}{llllllllll}\text { 2. SLF } & 4.56 & .69 & .94 & .89 & (.76-.81) & .63^{* *} & (.89)\end{array}$

$\begin{array}{llllllll}\text { 3. BSC } & 4.55 & .70 & .96 & .92 & (.84-.96) & .72 * * & .79 * *\end{array}$

Note:

SS=social support; $\mathrm{SLF}=$ self-efficacy; $\mathrm{BSC}=$ behavioral support for change.

$\mathrm{CR}=$ composite reliability.

Item loading $(\lambda)$ is standardized.

Values along the diagonal represent the square root of average variance extracted (AVE).

More conclusive specific tests of these hypotheses were conducted with structural equation modeling (SEM) analyses, using the AMOS software (Arbuckle, 2003) to assess the structural model specifying the relations between the latent constructs. Table 3 presents fit indices for the hypothesized model, along with an alternative model with which to test whether a fully mediating relationship exists between TL and BSC.

Table 3. Hypothesized \& Competitive model test

$$
\begin{array}{llllllll}
\mathrm{X}^{2} & \mathrm{df} & \mathrm{X}^{2} / \mathrm{df} & \Delta \mathrm{X}^{2} & \text { RMSEA } & \text { CFI } & \text { TLI } & \text { GFI }
\end{array}
$$

$\begin{array}{llllllll}\text { Hypothesized model } & 174.913 & 52 & 3.364 & .079 & .97 & .97 & .93\end{array}$

$\begin{array}{lllllllll}\text { Alternative Model } & 108.035 & 51 & 2.118 & 66.878 & .054 & .99 & .98 & .96\end{array}$

* Alternative Model only adds the direct path from TL to BSC. 
Results of comparison show that the hypothesized model adequately explains the data as indicated in Table 3 by a RMSEA of 0.079 , a CFI of 0.97 , a GFI of 0.93 , and TLI of 0.97, whereas the alternative model results in a significant improvement in model fit, with a RMSEA of 0.054 , a CFI of 0.99 , a GFI of 0.96 , and an TLI of 0.98 . This suggests that SLF only partially mediates the relationship between TL and BSC. That is, TL not only direct affects BSC, but also indirectly affects BSC via SLF.

Standardized parameter estimates for the best-fitting model (Hypothesized Model) are shown in Figure 1. For ease of presentation, only the structural model is presented rather than the full measurement model. Examination of the path coefficients reveals that TL is uniquely related to SLF in the positive direction and has significant direct associations with BSC; SLF is to BSC in the positive direction. Thus, both hypothesis 1 is supported and 2 is partially supported.

\section{Figure 1:Final Mbdel}

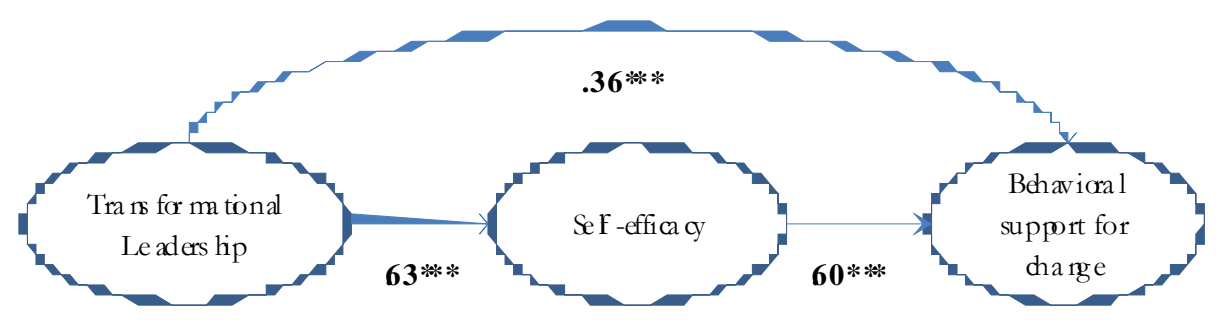

\section{Discussion}

The model presented in this study demonstrates that transformational leadership at the workplace in Taiwan is important in motivating employees' behavioral support for change directly and, indirectly, by enhancing employees' self-efficacy.

Additionally, the findings of this study indicate that transformational leadership functions as a means of enhancing control felt over some aspects of work demands during organizational change (i.e., high self-efficacy) which, in turn, encourages behavioral support for change. That is, this study points to the importance of transformational leadership in developing employees' attitudes (SLF in this case) and behaviors facilitating organizational change (BSC in this case). In short, transformational leadership may promote individuals' self-efficacy to exert behavioral efforts which contribute to their organization's successful implementation of change.

The present study has several practical implications for organizations, managers and HR practitioners facing organizational change. First, the findings of this study suggest that employees' behavioral support for organizational change can be enhanced by transformational leadership at the workplace. Recognizing the importance of transformational leadership during organizational change, managers and HR practitioners should consider how they might develop their supervisors/managers in a way of transformational leadership within their organizations via supportive policies and training programs with the ultimate intention of enhancing affective self-efficacy and behavioral support for change. 
Second, this study demonstrates that self-efficacy accounts for the variance in BSC. As such, organizations that plan changes or that are in the process of organization change should pay particular attention to enhancing their employees' self-efficacy. In particular, this can be done by training supervisors/managers to support a coaching environment (Gong, Huang, \& Farh, 2009; Malone, 2001), and by developing employees' competencies through training programs to strengthen their self-efficacy which, in turn, may encourage their BSC.

Third, during organizational change, it is critically important for organizations to identify employees with high self-efficacy as they are more prone to accept change and are better able to adapt to change (Schyns, 2004). Therefore, employees with high self-efficacy can serve as change agents for their colleagues, which is an integral requirement for any change strategy (Iverson, 1996), in order to increase the chances of the successful implementation of organizational change.

Like other studies, this study has certain limitations. First, the sample is confined to a limited number of companies (10) in Taiwan and 379 participants, which might in turn limit the generalizability of its findings and conclusions either to other enterprises. Second, despite the appropriateness of using subordinates' evaluations of transformational leadership, affective commitment to change and behavioral support for measures, this approach introduces potential problems with common-method bias as the measures of research variables were gathered from the same source, even though a Harmon single factor test (Podsakoff et al., 2003) shows that common method bias is not a serious problem in this study. Third, one must be cautious when interpreting the findings of this study due to the possible constraint of non-response bias, such that nonrespondents might hold different views with respect to the variables in question, leading to survey estimates that could be biased. Finally, this study suffers from the common limitations of cross-sectional field research, including the inability to make causal inferences.

Regarding the direction for future research, as noted by Podsakoff et al. (2003), using self-reported measures for both constructs may inflate their correlations due to selfreporting bias. Thus, future research should focus on supervisory ratings of BSC to reduce common method variance. That is, the use of immediate supervisors' assessments of subordinates' BSC would further validate the use of individuals' self-reported perceived transformational leadership and self-efficacy when investigating the relationships between transformational leadership and behavioral support for organizational change. Use of these supervisors' assessments would also lead to a better understanding of the effects of transformational leadership on behaviors through work attitudes.

\section{Conclusion}

In spite of the above mentioned limitations, this study has a number of strengths. First, as noted earlier, there has been a lack of empirical research on the role of transformational leadership in a change context per se. In this regard, the present study fills this gap by conducting an empirical research and the results indicate that transformational leadership at the workplace has significant and powerful influence on employees' supportive attitudes and behavior vis-à-vis organizational change. 
Second, as noted, improving our understanding of the relationship between transformational leadership and employees' reactions to organizational changes has become increasingly important given that many companies fail to implement organizational changes. In this regard, this study extends prior research by assessing a complex set of relations between transformational leadership, self-efficacy, and behavioral support for organizational change. Moreover, this study provides additional insight into the mechanism through which transformational leadership influences employee's behavioral support for organizational change.

Third, given that the vast majority of organizational change-related studies and leadership have been conducted in North American and other Western countries, the results of this research conducted in Taiwan, which add to our understanding of the relationship between transformational leadership and employees' self-efficacy, and behavioral support for organizational change in the Chinese context.

In summary, personal attitudes and emotions has been seen as the most important contributors to the management of organizational change (Graetz \& Smith, 2010; Kool \& van Dierendonck, 2012). However, little is known about the differential effects of various aspects of organizational factors on different elements of the attitudes of those individuals affected by change (Fedor et al., 2006). The model presented in this study demonstrates that Investigations of this kind can further enhance our ability to predict the effectiveness of organizational change efforts (Self, Armenakis, \& Schradeder, 2007). Moreover, given that available knowledge of how HR professionals perform effectively as "change agents" is relatively limited (Alfes, Truss, \& Gill, 2010), proving such linkages exist implies that, during organizational change, both management and HR practitioners should focus their efforts on promoting transformational leadership with the ultimate intention of enhancing the implementation of successful change.

\section{Reference}

Anderson, J. C. \& Gerbing, D. W. (1988), 'Structural equation modeling in practice: A review and recommended two-step approach', Psychological Bulletin, vol.103, no.3, pp.411-423.

Arbukle, J. L. (2003), AMOS 5.0 [computer software], SPSS, Chicago, IL.

Alfes, K., Truss, C., \& Gill, J. (2010). The HR Manager as Change Agent: Evidence from the Public Sector. Journal of change management, 10(1), 109-127.

Allen, J., Jimmieson, N. L., Bordia, P., \& Irmer, B. (2007). Uncertainty during Organizational Change: Managing Perceptions through Communication. Journal of change management, 7(2), 187-210.

Aselage, J., \& Eisenberger, R. (2003). Perceived organizational support and psychological contract: a theoretical integration. Journal of Organizational Behavior, 24, 491-509.

Ashford, S. J. (1988). Individual Strategies for Coping with Stress During Organizational transitions. The Journal of Applied Behavioral Science, 24(1), 19-36.

Bandura, A. (1982). Self-efficacy mechanisms in human agency. American psychologist, 37, 122-147.

Bandura, A. (1986). Social Foundations of Thought and Action. Englewood Cliffs, NJ.: Prestice-Hall.

Bandura, A. (1991). Social Cognitive Theory of Self-Regulation. Organizational Behavior and Human Decision Process, 50, 248-287.

Baron, R. M., \& Kenny, D. A. (1986). The moderator-mediator variable distinction in social psychological research: Conceptual, strategic, and statistical considerations. Journal of Personality and Social Psychology, 51, 1173-1182.

Caplan, G. (1974). Support systems and community mental health. New York: Behavioral Publications.

Chou, P. (2013). The Effect of Transformational Leadership on Follower's Affective Commitment to Change. World Journal of Social Sciences, 3(1), 38-52. 
Colquitt, J. A., Conlon, D. E., Wesson, M. J., Porter, O. L., \& Ng, K. Y. (2001). Justice at the Millennium: A Meta-Analytic Review of 25 years of Organizational Justice Research. Journal of Applied Psychology, 86(3), 425-445.

Daniels, K., \& Guppy, A. (1994 ). Occupational Stress, Social Support, Job Control, and Psychological wellbeing Human Relations, 47, 1523-1544.

Deelstra, J. T., Peeters, M. C. W., Schaufeli, W. B., Stroebe, W., zijlstra, F. R. H., \& Van Doornen, L. P. (2003). Receiving instrumental support at work: When help is not welcome. Journal of Applied Psychology, 88, 324-331.

Doby, V. J., \& Caplan, R. D. (1995). Organizational stress as threat to reputation: effects on anxiety at work and at home. Academy of Management Journal, 38( 4 ), 1105-1123.

60

Dvir, T., Kass, N., \& Shamir, B. (2004). The emotional bond: vision and organizational commitment among high-tech employees. Journal of Organizational Change Management, 17(2), 126-143.

Fedor, D. B., Caldwell, S., \& Herold, D. M. (2006). The effects of organizational changes on employee commitment: A multilevel investigation. Personnel Psychology, 59, 1-19.

Fornell, C. R., \& Larcker, D. F. (1981). Structural equation models with unobservable variables and measurement error. Journal of Marketing Research, 18(3), 39-50.

Ford, J. K., Weissbein, D. A., \& Plamondon, K. E. (2003). Distinguishing organizational from strategy commitment: Linking officers'commitment to community policing to job behaviors and satisfaction Justice Quarterly, 20, 159-185.

Gong, Y., Huang, J. C., \& Farh, J. L. (2009). Employee Learning Orientation, Transformational Leadership, and Employee Creativity: The Mediating Role of Employee Creative Self-Efficacy. Academy of Management Journal, 52(4), 765-778.

Graetz, F., \& Smith, A. C. T. (2010). Managing Organizational Change: A Philosophies of Change Approach. Journal of change management, 10(2), 135-154.

Griffin, M. A., Patterson, M. G., \& West, M. A. (2001). Job satisfaction and teamwork: the role of supervisor support. Journal of Organizational Behavior, 22, 537-550.

Hair, J. J. F., Anderson, R., Tatham, R. L., \& Black, W. C. (2006). Multivariate Data Analysis (6th ed.). Englewood Cliffs, NJ: Prentice Hall International Editions.

Herold, D. M., Fedor, D. B., \& Caldwell, S. D. (2007). Beyond change management: A Multilevel investigation of contextual and personal influences on employees' commitment to change. Journal of Applied Psychology, 92(4), 942-951.

Herold, D. M., Fedor, D. B., Caldwell, S. D., \& Liu, Y. (2008). The effects of transformational leadership and change leadership on employees' commitment to a change. Journal of Applied Psychology, 93(2), 346-357.

Herscovitch, L., \& Meyer, J. P. (2002). Commitment to Organizational change: Extension of a ThreeComponent Model. Journal of Applied Psychology, 87(3), 474-487.

Higgs, M. J., \& Rowland, D. (2005). All Changes Great and Small: Exploring Approaches to Change and its Leadership. Journal of change management, 5(2), 121-151.

House, J. S. (1981). Work stress and social support. MA: Addison-Wesley.

Iverson, R. D. (1996). Employee acceptance of organizational change: the role of organizational commitment. The international Journal of Human Resource Management 7(1), 122-149.

Jaros, S. (2010). Commitment to Organizational Change: A Critical Review. Journal of Change Management, 10(1), 79-108.

Jaskyte, K. (2003). Assessing Changes in Employees' perceptions of Leadership Behavior, job Design, and organizational Arrangements and their job satisfaction and commitment. Administration in Social Work, 27(4), 25-39.

Jimmieson, N. L., Terry, D. J., \& Callan, V. J. (2004). A Longitudinal Study of Employee Adaptation to organizational Change: The role of change-related information and change-related self-efficacy. Journal of Occupational Health Psychology 9(1), 11-27.

Joe, S. W. (2010). Assessing job self-efficacy and organizational commitment considering a mediating role of information asymmetry. The Social Science Journal, 47, 541-559.

Judge, T. A., Thoresen, C. J., Pucik, V., \& Welbourne, T. M. (1999). Managerial Coping with Organizational Change: A Dispositional Perspective. Journal of Applied Psychology, 84(1), 107-122.

Kelly, J. G., Munoz, R. F., \& Snowden, L. R. (1979). Characteristics of community research projects and the implemention process. In R. F. Munoz, L. R. Snowden \& J. G. Kelly (Eds.), Social and Psychological research in community settings. San Francisco: Jossey-Bass. 
Kirk, R., \& Dijk, D. (2007). Motivation to lead, motivation to follow: the role of the self-regulatory focus in leadership processes. Academay of Management Review, 32, 500-528.

Kool, M., \& van Dierendonck, D. (2012). Servant leadership and commitment to change, the mediating role of justice and optimism. Journal of Organizational Change management, 25(3), 422-433.

Lamm, E., \& Gordon, J. R. (2010). Empowerment, Predisposition to Resist Change, and Support for Organizational Change. Journal of Leadership \& Organizational Studies, 17(4), 426-437.

Landis, R. S., Beal, D. J., \& Tesluk, P. E. (2000). A comparison of approaches to forming composite measures in structural equation models. Organizational Research Methods, 3, 186-207.

Lau, C. M., \& Woodman, R. W. (1995). Understanding Organizational Change: A Schematic Perspective. Academy of Management Journal 38(2), 537-554.

Leana, C. R., \& Barry, B. (2000). Stability and Change as simultaneous experiences in organizational life. Academy of Management Review, 25(4), 753-759.

Levinson, H. (1965). Reciprocation: The relationship between man and organization. Administrative Science Quarterly, 9(4), 370-390.

Lin, N., Ensel, W. M., Simeone, R. S., \& Kuo, W. (1979). Social Support,Stressful Life Events, and Illness: A model and an Empirical Test. Journal of Health and Social Behavior, 20, 108-119.

Liu, Y., \& Ipe, M. (2010). The impact of organizational and leader-member support on expatriate commitment. The international Journal of Human Resource Management, 21(7-9), 1035-1048.

Lu, L., Gilmour, R., \& Kao, S. F. (2001). Cultural Values and Happiness: An East-West Dialogue. The Journal of Social Psychology, 141(4), 477-493.

Malone, J. W. (2001). Shining a new light on organizaitonal change: Improving self-efficacy through coach. Organizational developmen Journal, 19(22), 27-36.

Mathieu, J. E., \& Farr, J. L. (1991). Further evidence for the discriminant validity of measures of organizational commitment, job involvement, and job satisfaction. Journal of Applied Psychology, 76, 127-133.

Meyer, J. P., \& Allen, N. J. (1991). A Three-component conceptualization of orgnaizational commitment. Human Resource Management Review, 1(1), 61-89.

Meyer, J. P., \& Herscovitch, L. (2001). Commitment in the workplace Toward a general model. Human Resource Management Review, 11, 299-326.

Meyer, J. P., Srinivas, E. S., Lai, J. B., \& Topolnytsky, L. (2007). Employee commitment and support for an organizational change: test of the three-component model in tow culture. Journal of Occupational and Organizational Psychology, 80(2), 185-211.

Michel, A., Stemaier, R., \& Salvador, R. (2010). I Scratch Your Back - You Scratch Mine. Do Procudural Justice and Orgnaizational Idenfication Matter for Employees' Cooperation During Change? Journal of change management, 10(1), 41-59.

Miller, V. D., Johnson, J. R., \& Grau, J. (1994). Antecedents to willingness to participate in a planned organizational change. Journal of Applied Communication Research, 22, 59-80.

Mowday, R. T., Porter, L. W., \& Steers, R. M. (1982). Employee-organization linkages New York: Academic Press.

Oreg, S. (2003). Resistance to Change: Developing an Individual Differences Measure. Journal of Applied Psychology, 88(4), 680-693.

Orth, M. S. (2002). Factors related to resistance and support of organizational change. Doctoral Dissertation, Colorado State University, Dissertation Abstracts International, 63(26-35).

Parish, J. T., Cadwallader, S., \& Busch, P. (2007). Want, need to.ought to: employee commitment to organizational change. Journal of Organizational Change Management 21(1), 32-52.

Podsakoff, P. M., MacKenzie, S. B., Lee, J. Y., \& Podsakoff, N. P. (2003). Common method biases in behavioral research: A critical review of the literature and recommended remedies. Journal of Applied Psychology, 88, 879-903.

Sarason, I. G., Levine, H. M., Basham, R. B., \& Sarason, B. R. (1983). Assessing Social Support: The Social Support Questionnaire. Journal of Personality and Social Psychology, 44(1), 127-139.

Schaubroeck, J., \& Merritt, D. E. (1997). Divergent effects of job control on coping with work stressors: the key role of self-efficacy. Academy of Management Journal, 40(3), 738-754.

Schyns, B. (2004). The Influence of Occupational self-efficacy on the Relationship of Leadership Behavior and Preparedness for Occupational Chnage. Journal of career Development, 30(4), 247-261.

Self, D. R., Armenakis, A. A., \& Schradeder, M. (2007). Organizational Change Content, Process, and Context: A Simultaneous Analysis of Employee Reaction. Journal of change management, 7(2), 211229. 
Sosik, J. J., \& Godshalk, V. M. (2000). Leadership styles, mentoring functions received, and job-related stress: a conceptual model and preliminary study. Journal of Organizational Behavior, 21, 365-390.

Sundin, L., Bildt, C., Lisspers, J., Hochwalder, J., \& Setterkubd, S. (2006). Organisational factors,individual characteristics and social support: What determines the levels of social support. Work, 27(1), 4555.

Taylor, B. L., Delcampo, R. G., \& Blancero, D. M. (2009). Work-family conflict/facilitation and the role of workplace supports for U.S. Hispanic professionals. Journal of Organizational Behavior, 30, 643-664.

Tierney, P., \& Farmer, S. M. (2002). Creative Self-Efficacy: Its Potential Antecedents and Relationship to Creative Performance. Academy of Management Journal, 45(6), 1137-1148.

Van den Heuvel, M., Demerouti, E., Schreurs, B. H. J., Bakker, A. B., \& Schaufeli, W. B. (2009). Does meaning-making help during organizational change? Development and validation of a new scale. Career Development International, 14(6), 508-533.

Wanberg, C. R., \& Banas, J. T. (2000). Predicators and Outcomes of Openness to Changes in a Reorganizing Workplace. Journal of Applied Psychology, 85(1), 132-142.

Witt, L. A., Kacmar, K. M., \& Andrews, M. C. (2001). The interactive effects of procedural justice and exchange ideology on supervisor-rated commitment. Journal of Organizational Behavior 22, 505-515.

Yousef, D. A. (2000). Organizational commitment and job satisfaction as predictors of attitudes toward organizational change in a non-western setting. Personnel review, 29(5), 567-592. 